\title{
Estimating corrosion attack in reinforced concrete by means of crack opening
}

The corrosion of reinforcement in concrete is the most common degradation phenomenon of reinforced concrete structures. Reinforced concrete elements subjected to corrosion generally crack due to the expansive nature of oxides. One very important task is estimating the corrosion level using a non-destructive method in order to establish both the actual safety of the structure and a priority intervention plan.

Many researchers have studied the relationship between the corrosion phenomenon and the corresponding crack openings and their evolution; several statistical analyses, based on test data from experimental campaigns under a wide range of test conditions, are available.

The present work attempts to contribute to finding a relationship between the crack opening and the amount of corrosion induced in the reinforcing bars. The result of the analysis is that only a reduced number of tests can be used to establish an empirical model based on a reliable set of test data. A simple relationship between crack opening and corrosion penetration is not recommended, due to the different parameters that are able to influence this correlation. Therefore, two fundamental parameters, the ratio of the concrete cover to the rebar diameter and the concrete strength, have also been considered. The considerations made regarding these parameter test results have been rearranged and the result is a formulation that shows reduced scatter.

Keywords: crack opening, reinforcement corrosion, safety assessment

\section{1}

\section{Introduction}

The corrosion of reinforcement in concrete is one of the main detrimental problems for reinforced concrete (RC) structures. Its principal effects are:

i) a reduction in the resisting section of the reinforcing bars,

ii) damage to and cracking of the concrete surrounding the bars, caused by the expansion of the oxides,

iii) impairment of the bond between the reinforcement and the concrete, and

\footnotetext{
* Corresponding author: francesco.tondolo@polito.it
}

Submitted for review: 30 July 2015; revision: 23 December 2015; accepted for publication: 08 January 2016. Discussion on this paper must be submitted within two months of the print publication. The discussion will then be published in print, along with the authors' closure, if any, approximately nine months after the print publication. iv) the modification of the constitutive relationship of the corroded reinforcement in terms of stress-strain relationship and fatigue resistance.

Therefore, corrosion is able to impair the structural behaviour of an RC structure to a great extent. Under service conditions, corrosion influences the stiffness of the elements, due to variations in the bond-slip relationship after cracking of the concrete [1]. In particular, it is evident that, for low values of corrosion attack, it is possible to observe an increase in stiffness in the response under mechanical action, whereas for values that exceed a threshold value, which is generally assumed to be the level of corrosion able to produce crack formation on the outer concrete surface, a reduction in stiffness is mainly observed as a consequence of the reduction in bond [2]. At ultimate conditions, corrosion, other than being able to reduce the load bearing capacity, could also be responsible for modifications to the collapse mechanism. For example, shear failure can precede flexural failure [3], because of the effect of the reduction in the resisting area of the stirrups, which are the rebars nearest to the external surface. This could determine a transition from a ductile to a brittle type of failure. Furthermore, shear collapse can be attributed to the interaction between shear and bending mechanisms in the presence of corrosion as demonstrated in Ghersi et al. [4]. This issue could be particularly critical in the presence of seismic actions, in which case ductile behaviour is needed.

The detection of damage due to the corrosion of reinforcement is facilitated by the appearance of cracks on the surface of the element. Such cracks are caused by tensile stresses created by the expansive rust oxides, which are caused by the loss of passivity, which in turn is determined by a concentration of chlorides or by the carbonation of concrete. The rust formed acts like a gel that, through the cracks, reaches the concrete surface. However, stains on the surfaces or signs of drainage from hidden zones due to corrosion point out the presence of damage.

Cracks on the surface are visible, measurable and reveal the presence of a corrosion attack; their width is, in general, related to the level of reinforcement corrosion and to the density of bars in that area, as has been observed by several authors [5]. However, from an analysis of the experimental results available in the literature, it is evident that the correlation between crack opening and 
corrosion level shows a huge scattering. In [6], [7], [8] and [9] it has been underlined that, among other factors, the main influencing variables are the corrosion rate itself, the concrete microstructure and its strength, the ratio between concrete cover and bar diameter and the presence of confinement, which could act to prevent crack formation and its evolution. The variability in the corrosion attack penetration along the length of a crack opening could be also important [9], [10], even though it is generally considered to be constant. It is important to emphasize that localized corrosion may have a significant influence on the tensile strength of the reinforcing bars even though pitting corrosion can hardly be linked to uniform corrosion as some authors have shown due to highly scattered data [11], [12]. In order to correlate the measured crack widths on the surface of an RC element to the corresponding entity of corrosion, the influence of the aforementioned factors should not be disregarded.

In the present paper, an analysis of the results from the literature will be made in order to identify the possible relations between crack width and several variables and summarize the influences mathematically. Although a direct universal relation between crack width and degree of corrosion seems very difficult to reach, the present work tries to contribute to exploring the key influencing parameters.

\section{Analysis of the experiments in the literature}

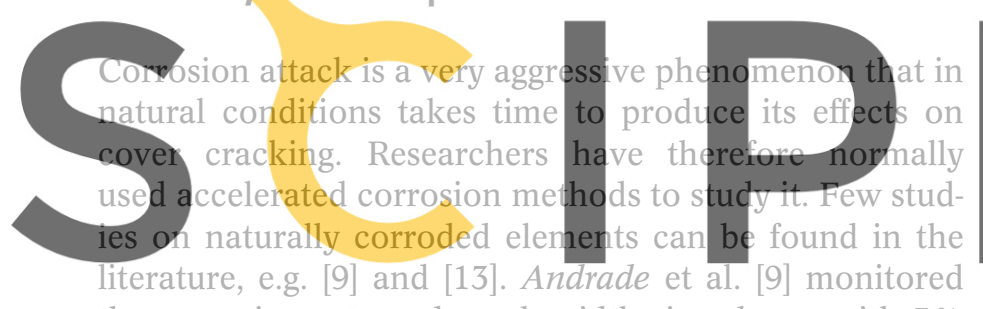
the corrosion rate and crack widths in a beam with $3 \%$

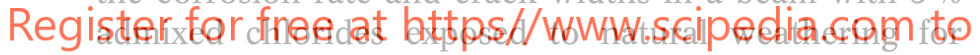
more than 20 years. The results indicate that although there is a linear relationship between crack width and time, the relation between crack width and corrosion rate was not unique, with the cracks varying from $<1 \mathrm{~mm}$ to $14 \mathrm{~mm}$. Torres-Acosta and Martinez-Madrid [13] conducted a study on twelve $90 \times 190 \times 305 \mathrm{~mm}$ RC slabs with three $13 \mathrm{~mm}$ diameter bars and $25 \mathrm{~mm}$ concrete cover. The corrosion was of a natural type in a marine environment and an activated titanium electrode was used to evaluate the amount of current flowing into the concrete. The specimens were subjected to marine exposure for about 700 days. At the end of each test, the cracks were mapped and the average corrosion attack was measured. The maximum value of mass loss was $17.9 \%$. Zhang et al. [14] obtained results on crack formation and bond variation between steel and concrete in naturally corroded RC elements subjected to an aggressive environment for more than 20 years. Other than the difficulties encountered with very long experimental tests, the possibility of analysing real structures is hindered because they are generally still in service. Therefore, tests with accelerated corrosion methods are needed and they are usually the only way of studying this phenomenon. In structures subjected to accelerated corrosion, some authors (Rodriguez et al. [15]) observed that the current density flowing into the reinforcing bars can be highly variable, depending on the test conditions (wet/dry). Other accelerated corrosion tests ([7] and [16]) have dealt with the effect of current density variations on the formation of the first crack and its evolution overtime. The authors have observed that it is possible to obtain very different oxide products from corrosion, depending on the current density that is applied and the moisture conditions. Additionally, these oxides show different expansion coefficients from those that characterize the formation of a "natural" corrosion product.

Andrade et al. [17] recorded corrosion rates in natural and laboratory conditions in different environments. The maximum current densities registered were about $100 \mu \mathrm{A} / \mathrm{cm}^{2}$, corresponding to cracked concrete in contact with seawater. This is also a normal current in the steel in other environments, indicating that higher levels of current density, if applied in accelerated corrosion tests, generally lead to the formation of oxide products with a lower density than those products obtained with low levels of current density. The structural effect of this volumetric variation of the accelerated mechanism is perceived as the formation of a crack on the surface, which could be of a small width due to the low pressure exhibited by the oxide product.

In addition to Andrade, other authors, e.g. Clark and Saifullah [18], also suggested using a current density $250 \mu \mathrm{A} / \mathrm{cm}^{2}$, because higher current density values

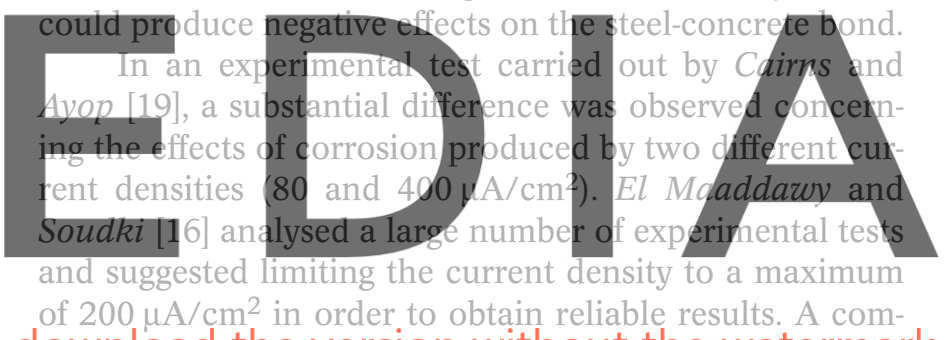

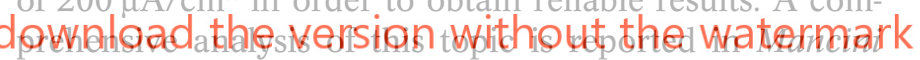
and Tondolo [20].

On the basis of previous considerations, only some experimental tests whose accelerated level of the current density was $<200 \mu \mathrm{A} / \mathrm{cm}^{2}$ will be commented on here. They are summarized in Table 1.

Andrade et al. [5] conducted experimental tests on $150 \times 150 \times 380 \mathrm{~mm}$ specimens with $16 \mathrm{~mm}$ diameter reinforcing bars and 20-30 mm concrete covers. Crack openings were measured using electric strain gauges glued to the external surface of the specimens. The electrochemical corrosion was obtained with a current density ranging between 10 and $100 \mu \mathrm{A} / \mathrm{cm}^{2}$. An average $3.55 \mathrm{MPa}$ tensile strength was evaluated for the concrete.

Research on cubic specimens, with reinforcing bars positioned at the corners, was presented in Rodriguez et al. [34]; the presence of transverse confinement was also studied. This kind of specimen, named "end beam element", reproduces a portion of the beam subjected to constant shear. The specimens had a cubic shape with 16 and $10 \mathrm{~mm}$ diameter ribbed bars and 8 or $6 \mathrm{~mm}$ diameter stirrups. The ratios of cover to diameter $(\mathrm{c} / \phi)$ were 1.5 and 2.5 and the mean compressive strength of the concrete was $40 \mathrm{MPa}$. The elements were subjected to a current density of $100 \mu \mathrm{A} / \mathrm{cm}^{2}$. At the end of the corrosion process, the specimens were analysed carefully and the crack 
patterns mapped. An evaluation of the corrosion penetration attack was obtained by means of a gravimetric procedure.

The results of the tests on eight beam specimens measuring $152 \times 254 \times 3200 \mathrm{~mm}$ are reported in $E l$ Maaddawy et al. [21]. Some specimens were simultaneously corroded and loaded in a four-point bending test, whereas the others were first corroded and then loaded. The reinforcement was in the form of two $15 \mathrm{~mm}$ diameter ribbed bars in the tension zone, two plain $8 \mathrm{~mm}$ diameter bars in the compression zone and plain $8 \mathrm{~mm}$ stirrups at $80 \mathrm{~mm}$ spacing along the shear span and $333 \mathrm{~mm}$ in the central part. The concrete cover was $33 \mathrm{~mm}$ and a current density of $165 \mu \mathrm{A} / \mathrm{cm}^{2}$ was used to corrode the bottom bars. Corrosion levels of 8.9 and $31.6 \%$ of mass loss were achieved. At the end of this process, the cracks were measured and mapped.

The experimental study reported in Torres-Acosta et al.[12] shows 12 reinforced $100 \times 150 \times 1500 \mathrm{~mm}$ concrete beams with $9.5 \mathrm{~mm}$ diameter ribbed bars and $20 \mathrm{~mm}$ concrete cover. The accelerated corrosion was obtained by means of a constant current density of $80 \mu \mathrm{A} / \mathrm{cm}^{2}$. The current was applied for the time necessary to obtain an average reduction equal to 5,10 and $15 \%$ of bar radius. A custom-made multichannel galvanostat provided a regulated current source for each specimen. The mean compressive strength tested on the concrete cylinders was $27 \mathrm{MPa}$. At the end of the corrosion period, the crack po-

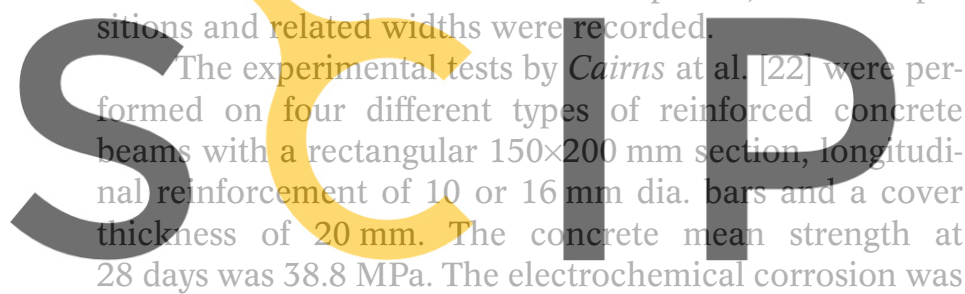
obtained by means of a current density of $60 \mu \mathrm{A} / \mathrm{cm}^{2}$ ap.

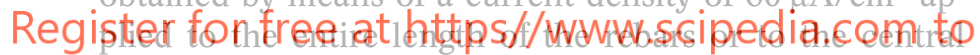
part of them depending on the type of specimen. The authors observed the specimens continuously in order to register the onset of cracking, which was measured by means of a mechanical extensometer. The mass loss ranged between 7.0 and $11.5 \%$.

The results of an experimental campaign on reinforced concrete elements are reported in Al-Harthy et al. [23]. The experiment was designed to investigate how the transverse reinforcement, the $\mathrm{c} / \phi$ ratio and the longitudinal reinforcement influence crack formation. Slab elements with dimensions of $250 \times 550 \times 1000 \mathrm{~mm}$ were tested. The longitudinal reinforcement had a diameter of 16 or $27 \mathrm{~mm}$, the concrete cover was 10 or $20 \mathrm{~mm}$ and the mean compressive strength of the concrete was $23.4 \mathrm{MPa}$. The corrosion was obtained by means of three different current densities of 59,100 and $169 \mu \mathrm{A} / \mathrm{cm}^{2}$, applied for a maximum period of $1860 \mathrm{~h}$. The crack widths were measured using a mechanical strain gauge and they were evaluated, after demolishing the specimens, according to the ASTM G1-03 [24] procedure.

The results of an experimental survey of reinforced concrete specimens are reported in Coronelli et al. [25]. The specimens were end-beam elements, in agreement with a shear cracking scheme, reinforced with three ribbed $20 \mathrm{~mm}$ diameter steel bars. Two types of specimen were employed: with and without transverse bars. The stirrups for the former group were ribbed $8 \mathrm{~mm}$ diameter bars spaced $40 \mathrm{~mm}$ apart. The $\mathrm{c} / \phi$ ratio was 1.5 , the bonded length $210 \mathrm{~mm}$ and the current density for the accelerated corrosion $143 \mu \mathrm{A} / \mathrm{cm}^{2}$, a value that was maintained for a period of time necessary to reach the $10 \%$ mass reduction in the longitudinal reinforcement calculated with Faraday's law. The mass reduction was checked a posteriori by weight loss measurement. The crack formation and its evolution were monitored continuously.

The experimental campaign reported in Richard et al. [26] was conducted for rectangular $250 \times 100 \times 1000 \mathrm{~mm}$ beam elements with two $20 \mathrm{~mm}$ longitudinal bars. The concrete cover was $25 \mathrm{~mm}$. A constant current density of $100 \mu \mathrm{A} / \mathrm{cm}^{2}$ was used for a period of about 700 hours. Corrosion only took place in the central $500 \mathrm{~mm}$ section of the beam. The crack width evolution was measured daily.

Twenty-eight "beam-end"-type pull-out tests were analysed in Prieto [27] in order to study the effect of corrosion on the bond properties between steel and concrete. Three different specimen typologies were prepared (confined with transverse reinforcement, confined using external pressure and unconfined) and subjected to a current density ranging between 100 and $200 \mu \mathrm{A} / \mathrm{cm}^{2}$ in order to reach corrosion percentages of up to $9 \%$ in terms of mass loss. The test setup gave results for the bar position chosen during the casting and on the concrete cover, whose ratio with respect to

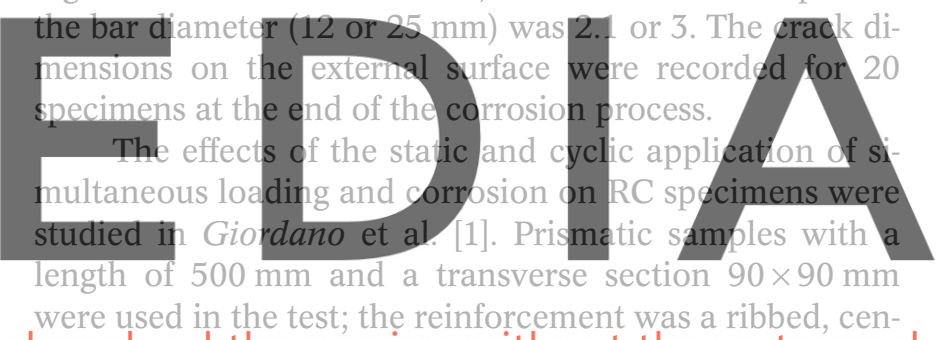

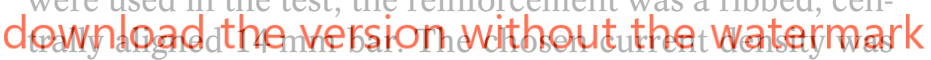
$200 \mu \mathrm{A} / \mathrm{cm}^{2}$ and each test lasted 25 days. Static and cyclic tensile forces were applied; in the latter case $6.5 \times 10^{6} \mathrm{cy}$ cles were induced. The value of the crack opening was measured continuously during the test.

In 2014 some of the authors of the present paper performed pull-out tests on reinforced concrete specimens subjected to corrosion in the "Franco Levi" Laboratory at Politecnico di Torino. The specimens were $120 \mathrm{~mm}$ cubes that were reinforced with one ribbed $12 \mathrm{~mm}$ diameter bar according to RILEM pull-out recommendations. The bar embedment length was $60 \mathrm{~mm}$ and a ratio of cover to rebar diameter of 4.5 was used. A current density of $200 \mu \mathrm{A} /$ $\mathrm{cm}^{2}$ was used for the time needed to reach theoretical mass losses of 2, 5, 10 and $20 \%$. At the end of the corrosion procedure, during which the crack width evolution was monitored, pull-out tests were performed, and then the rust was removed according to ASTM G1-03 [24] in order to verify the actual mass losses, which were $2.5,6.0$, 10.6 and $24.8 \%$ respectively.

All the previous experimental results, summarized in Table 1, were collected under the specific condition of being subjected to natural corrosion or accelerated corrosion with a limited density $\left(200 \mu \mathrm{A} / \mathrm{cm}^{2}\right)$. However, it is possible to find a large number of tests in the literature [28], [29], [30], [31], [32] that do not fulfil this condition. A 
Table 1. Experimental tests used for the statistical analysis of crack opening due to corrosion with corrosion progression

\begin{tabular}{|c|c|c|c|c|c|}
\hline \multirow{2}{*}{ Research project } & \multirow{2}{*}{$\frac{J}{\left[\mathrm{~mA} / \mathrm{cm}^{2}\right]}$} & \multirow{2}{*}{$\frac{f_{c}}{[\mathrm{MPa}]}$} & \multirow{2}{*}{$\frac{f_{t}}{[\mathrm{MPa}]}$} & \multirow{2}{*}{$\frac{c / \phi}{[-]}$} & \multirow{2}{*}{$\begin{array}{l}\text { Simultaneous } \\
\text { application } \\
\text { of load }\end{array}$} \\
\hline & & & & & \\
\hline Andrade et al. (1993) & $10-100$ & - & 3.55 & $1.25 ; 1.9$ & NO \\
\hline Torres-Acosta \& Martinez-Madrid (2003) & natural corrosion & NA & 1.9 & 1.9 & NO \\
\hline Rodriguez et al. (2004) & 100 & 40 & NA & $1.9 ; 2.0 ; 2.1 ; 2.9$ & NO \\
\hline El Maaddawy et al. (2005) & 165 & 41 & NA & 2.2 & YES/NO \\
\hline Torres-Acosta et al. (2007) & 80 & 27 & 2 & 2 & NO \\
\hline Cairns et al. (2008) & 60 & 38.8 & NA & $1.6 ; 2.6$ & NO \\
\hline Al-Harthy et al. (2010) & $59 ; 100 ; 169$ & 23.8 & 8 & $0.37 ; 0.63 ; 0.74 ; 1.25$ & NO \\
\hline Coronelli et al. (2011) & 143 & 34.3 & NA & 1.5 & NO \\
\hline Giordano et al. (2011) & 200 & 25.2 & NA & 2.7 & YES \\
\hline Richard et al.(2012) & 100 & 44.7 & 3.3 & 1.25 & NO \\
\hline Prieto (2014) & $100 ; 150 ; 200$ & NA & $2 ; 2.3 ; 2.5$ & $2.1 ; 3 ; 4$ & NO \\
\hline Pull-out test in Turin (2014) & 200 & 33.2 & 3.4 & 4.5 & NO \\
\hline
\end{tabular}

further condition in the selection was a crack opening no greater than $2 \mathrm{~mm}$. This second condition was mainly chosen for two reasons: a dimension of $2 \mathrm{~mm}$ generally means a very large opening, so delamination is about to occur; additionally, the scattering of the results for crack widths $>2 \mathrm{~mm}$ is too high for a reliable statistical interpretation; in fact, only a few authors have reported cracks

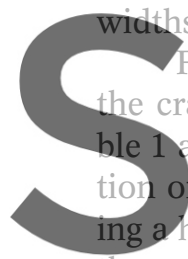
greater than the $2 \mathrm{~mm}$ lim or the sake of studying the openings of the expering are plotted in Fig. 1 on a homogeneous generalized cc
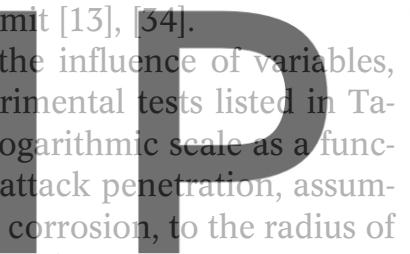

the reinforcement $\left(X_{a z e} / r_{0}\right)$ according to Torres-Acosta's proposal [13]. Indeed, the interpolation function of the

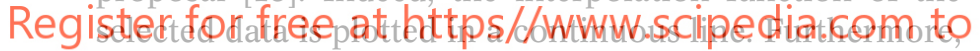

the interpolation function proposed by Torres-Acosta [13] is also drawn with a dashed line. It is important to note that the two interpolation functions were obtained from different sets of experimental data; in fact, some data used by Torres-Acosta are not included in the actual database. We interpreted that the larger current densities of the test setup, not included in this analysis but present in [13], are responsible for this discrepancy. For these tests, corrosion was obtained after a short time for values of current densities greater than $200-250 \mu \mathrm{A} / \mathrm{cm}^{2}$, but unlike for the test executed with low current densities, the system is unable to create expansive oxides. Furthermore, wet and dry moisture cycles could also modify such kinds of oxide products and they take time to become effective. The interpolation curve for the selected dataset is drawn in the same graph in Fig. 1, resulting in

$w_{\max }=11.13 \cdot\left(\frac{x_{\text {ave }}}{r_{0}}\right)^{0.827}$

Which corresponds to a coefficient of determination $\mathrm{R}^{2}$ equal to 0.705 . This curve was obtained by means of a linear regression using a power law. The shape of the curve is in line with that observed by other authors [25]. The function proposed by Torres-Acosta, and used in our work, shows a determination coefficient of 0.563 ; the higher coefficient of determination corresponding to our proposal is justified by the higher homogeneity of the tests considered. For visualization purposes, the same graph has also been plotted on a normal linear scale in order to point out the reduction in scattering obtained with Eq. (1).

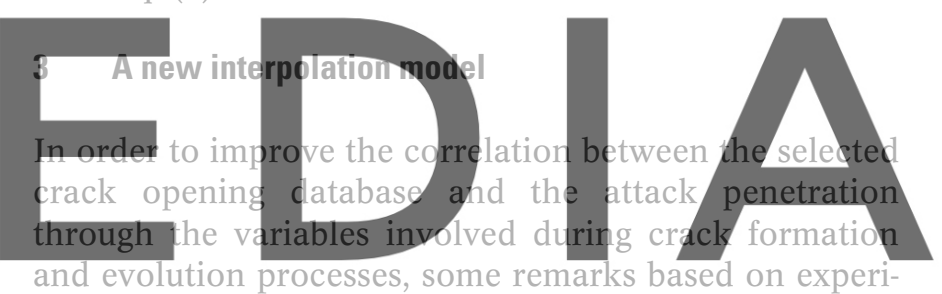

and evolution processes, some remarks based on experimental results and literature discussions are reported

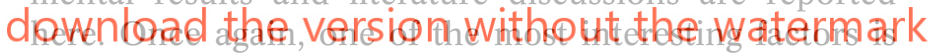

the ratio between concrete cover and bar diameter. In fact, with increasing corrosion penetration, a rebar with a large diameter produces cracks with a larger opening than a bar with a smaller diameter [33], assuming the same cover depth. The tensile strength of concrete is surely another parameter that influences the crack dimension; in fact, the higher the strength, the more likely it is that cracks due to the pressure of oxides are avoided, and once a crack appears, the more likely it is that its dimension remains smaller than in the case of a lowstrength concrete.

In order to take into account the previous considerations, a new overall parameter, named CT, has been introduced. This parameter is able to take into account the tensile strength of concrete and the $c / \phi$ ratio simultaneously [34]:

$C T=\left(\alpha \frac{c}{\phi}\right)^{-\frac{\beta}{f_{c t}}}$

where:

$c$ concrete cover

$\phi$ bar diameter

$f_{c t}$ average tensile strength of concrete [MPa] 


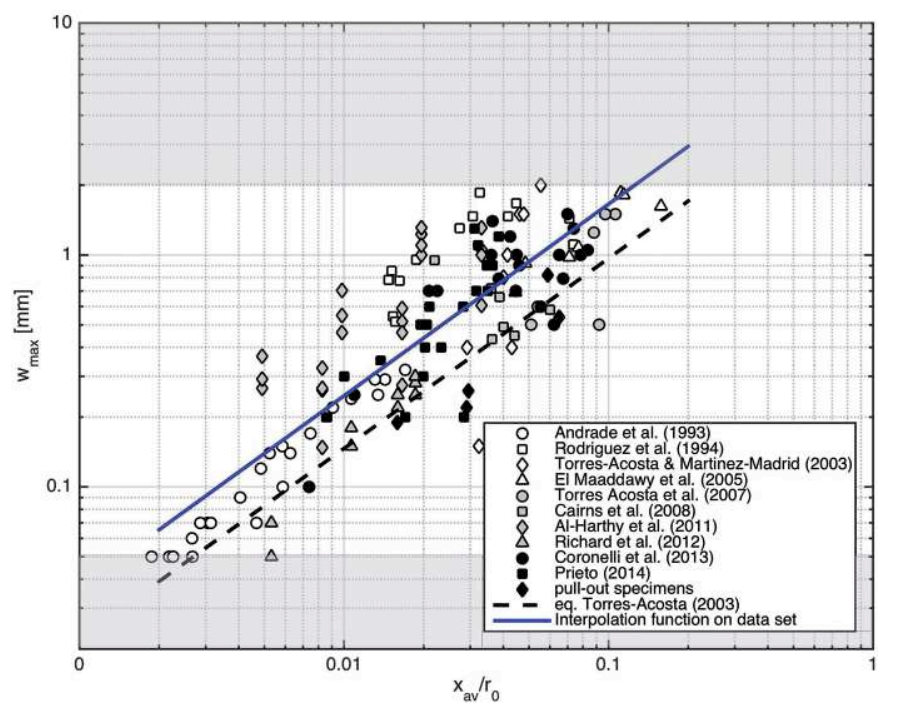

Fig. 1. Maximum crack openings with average attack penetration related to initial steel bar radius - logarithmic scale

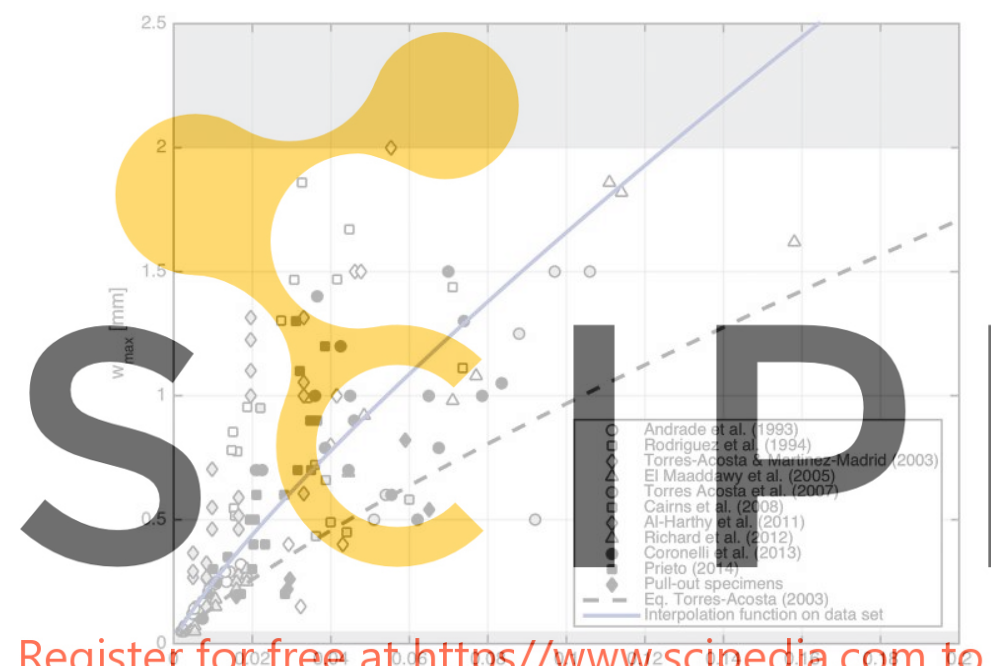

Register forofree at.https//WWw:scipedia.com to

Fig. 2. Miaximum crack openings vith average attack penetration related to initial steel bar radius - linear scale

In the absence of data, it is possible to use the relation from the fib Model Code for Concrete Structures 2010 [35]:

$f_{c t m}=0.3 \cdot\left(f_{c m}-8\right)^{2 / 3}$

where:

$f_{c m}$ average cylinder compression strength of concrete [MPa]

$\alpha, \beta$ two parameters that are determined by best fitting: $\alpha$ is dimensionless, $\beta$ is expressed in $\mathrm{MPa}$

The $C T$ parameter will be used as a multiplication factor for the $X_{a v e} / r_{0}$ ratio of the average attack penetration to the radius of the reinforcement.

As previously mentioned, the $\alpha$ and c values are calculated in order to minimize the coefficient of determination of the interpolation curve, considering the experimental data given in Table 1 . This procedure leads to values of 0.63 and $1.41 \mathrm{MPa}$ for $\alpha$ and $\beta$ respectively.

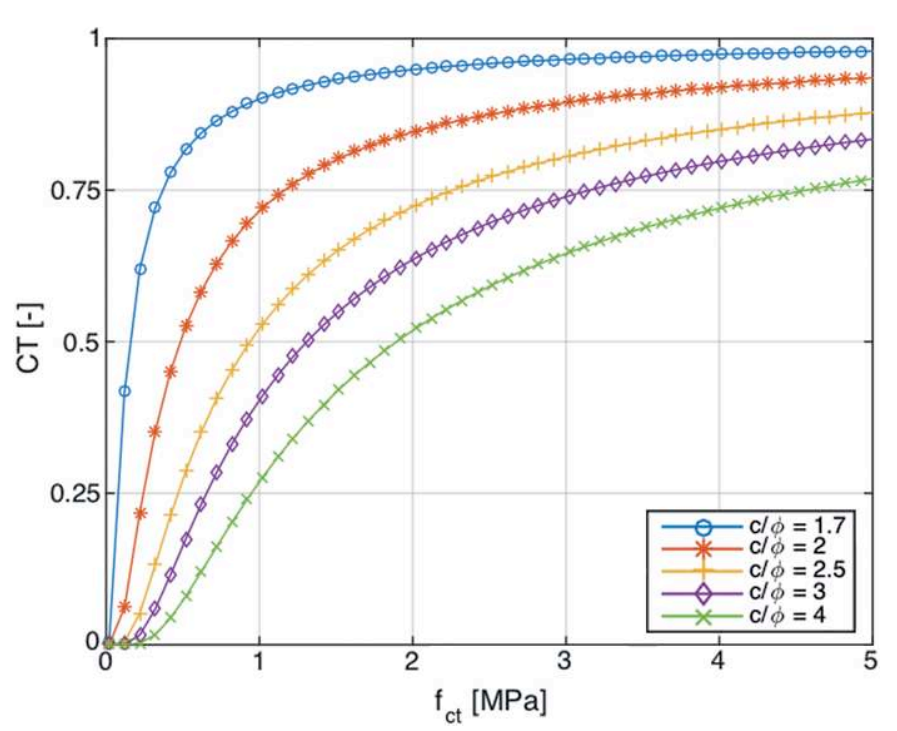

Fig. 3. $C T$ as a function of $f_{c t}$

The new interpolation function is expressed as follows:

$W_{\max }=15.863 \cdot\left(\frac{x_{\text {ave }}}{r_{0}} \cdot C T\right)^{0.928}$

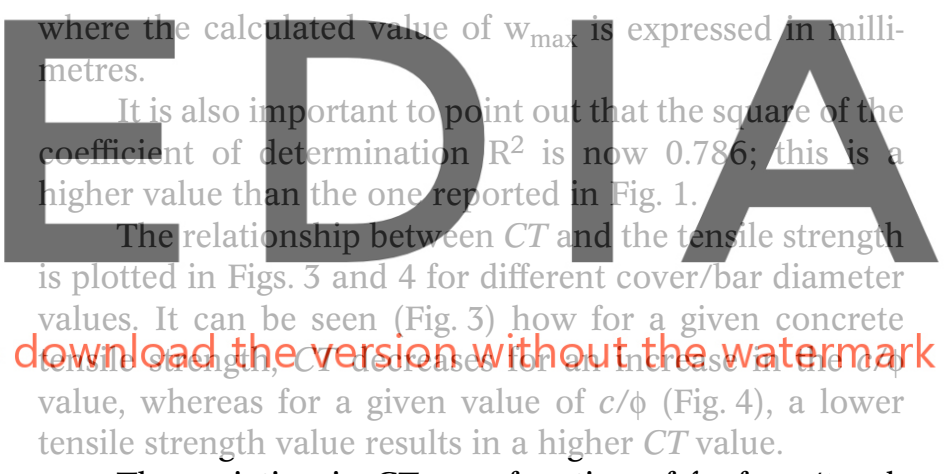

The variation in $C T$, as a function of $f_{c t}$, for $c / \phi$ values varying over a range 1.7-4 is depicted in Fig. 3.

The variation in $C T$, as a function of $c / \phi$, for tensile concrete strengths of 2, 3 and $4 \mathrm{MPa}$ is shown in Fig. 4.

From these last two graphs it is evident that the influence of the $c / \phi$ ratio is more important than the concrete strength when determining the $C T$ parameter.

Finally, the advantage of introducing the $C T$ factor can be seen in Fig. 5. A reduced scatter can be observed, compared with the previous analysis shown in Figs. 1 and 2 . This advantage is even more evident when the plot (Fig. 6) is performed on a logarithmic scale.

Furthermore, some experimental results obtained from two experimental tests performed by Giordano et al. [1], for which the specimens were loaded mechanically during corrosion, are presented in red and magenta in Fig. 7. The maximum and minimum values of the crack openings are reported for each test in order to show the maximum gap recorded for increasing corrosion levels. The first test refers to crack measurements for a specimen under simultaneous cyclic loading and corrosion, whereas the second one refers to a statically loaded specimen with simultaneous corrosion. The two 


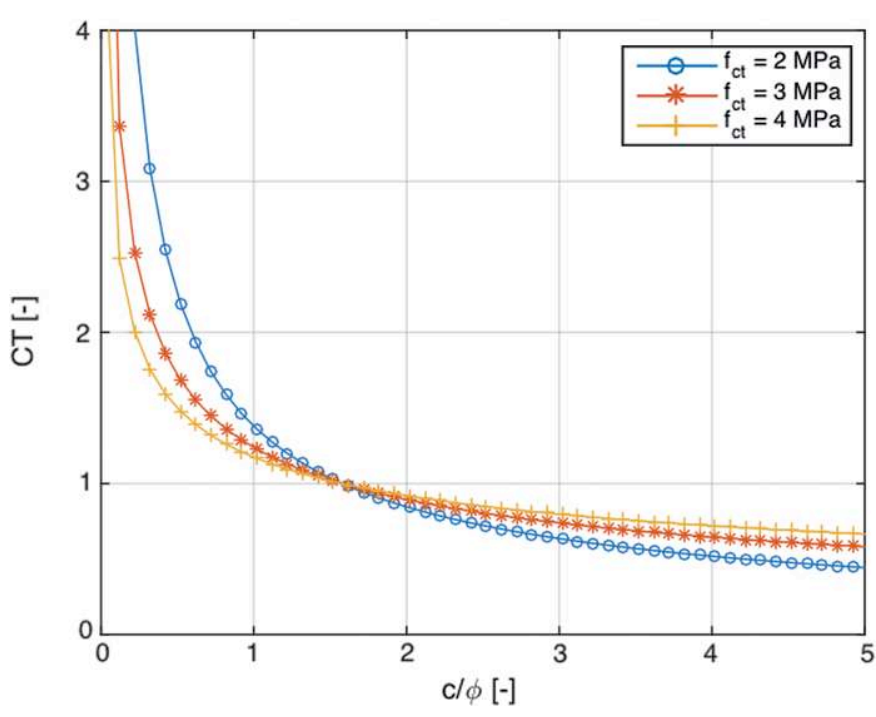

Fig. 4. $C T$ as a function of $c / \phi$

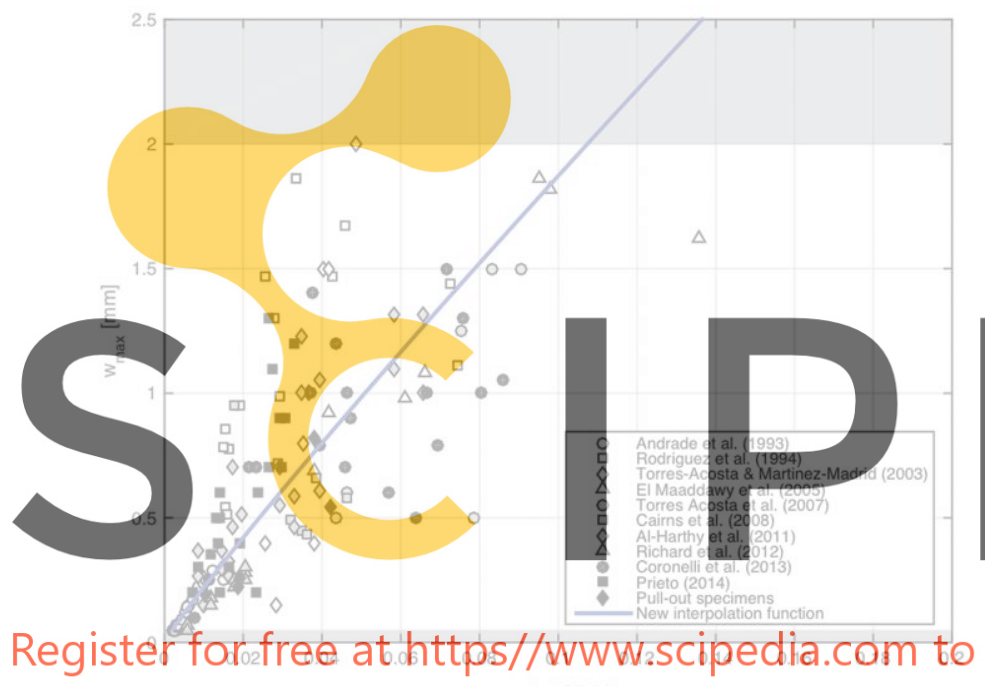

Fig. 5. Maximum crack openings with average attack penetration related to initial steel bar radius with correction parameter - linear scale

specimens were named FC60-50 and SC40-00 respectively in the paper. Upon formation of the first crack due to corrosion, the crack openings are in line with the results of the other experimental research and the interpolation function. As the test evolves, a higher crack width evolution rate can be seen for the specimen under cyclic loading compared with the specimen under static loading.

The functions obtained from a linear regression analysis, corresponding to a $95 \%$ confidence interval, are also shown in Fig. 7. The expression for the lower bound could be used to assess a deteriorated RC structure (on the safe side).

The results of test data obtained from other experimental tests, which have not been included in the database used for determining the interpolation function, are reported in Fig. 8 for comparison purposes. It is evident that this plot shows increased data scatter due to the nonhomogeneity of the added tests with respect to the first set

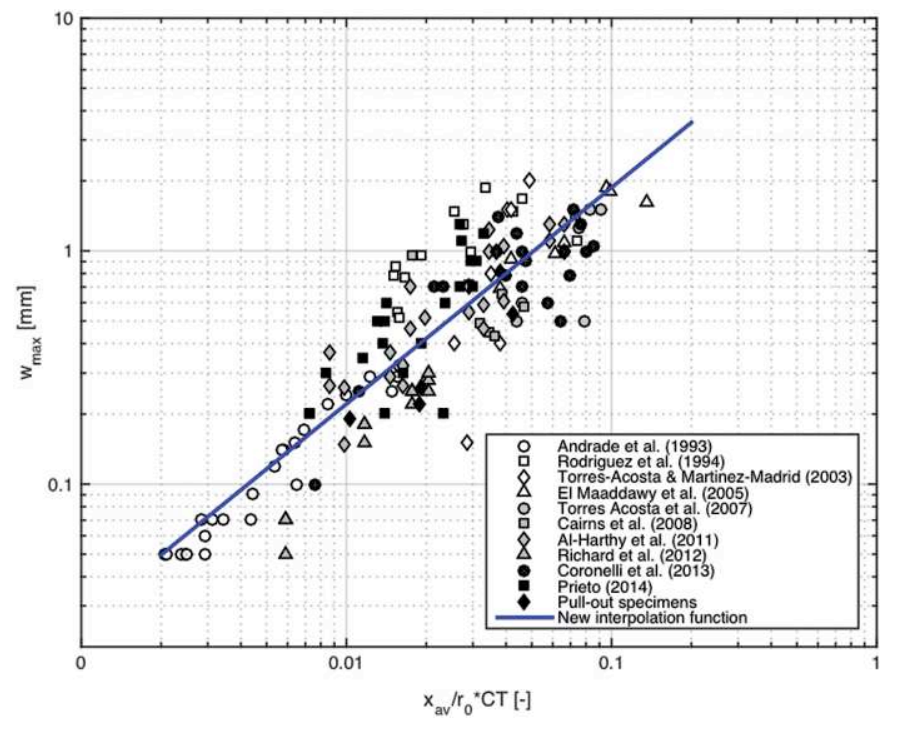

Fig. 6. Maximum crack openings with average attack penetration related to initial steel bar radius with correction parameter - logarithmic scale

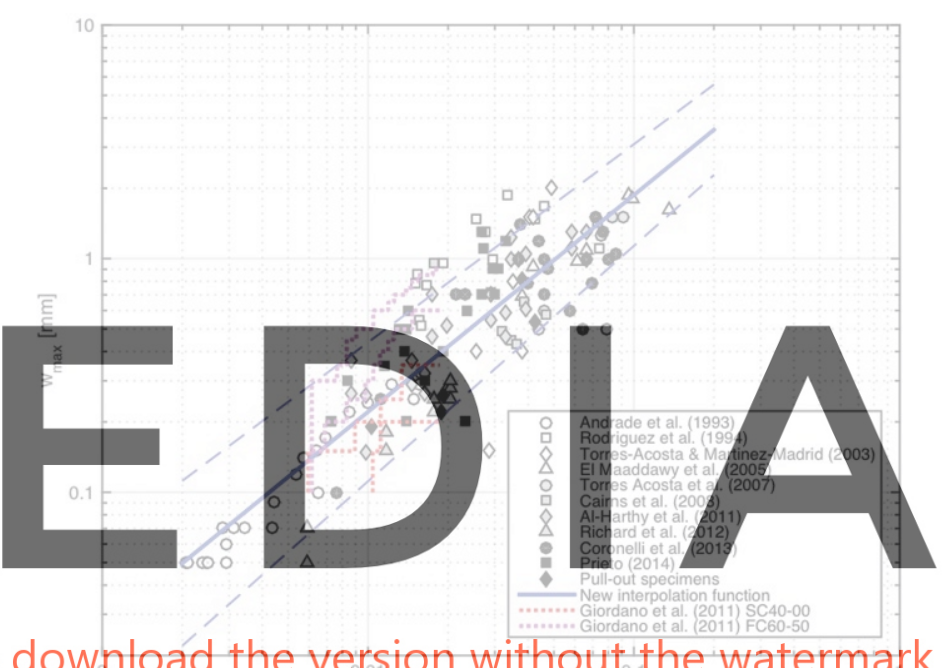

Fig. 7. Maximum crack openings with the average attack penetration related to initial steel bar radius with correction parameter - logarithmic scale

due to the effect of the excessively high current density used during the experiments.

\section{Conclusions}

The selection of the experimental tests and the analysis and use of the factors that influence the related results has allowed a new interpolation function to be determined for the accelerated corrosion tests relating crack width to corrosion level. This function could be used to estimate the attack penetration of reinforcing steel bars in accelerated tests when a corrosion crack is produced on the external surface of the structural element. The function takes into account the influence of the concrete cover as well as that of the tensile strength of the concrete and the bar diameter. The presence of a new parameter $C T$ determines the higher correlation of the results. It is important to state that this analysis is obviously valid only for accelerated tests in the presence 


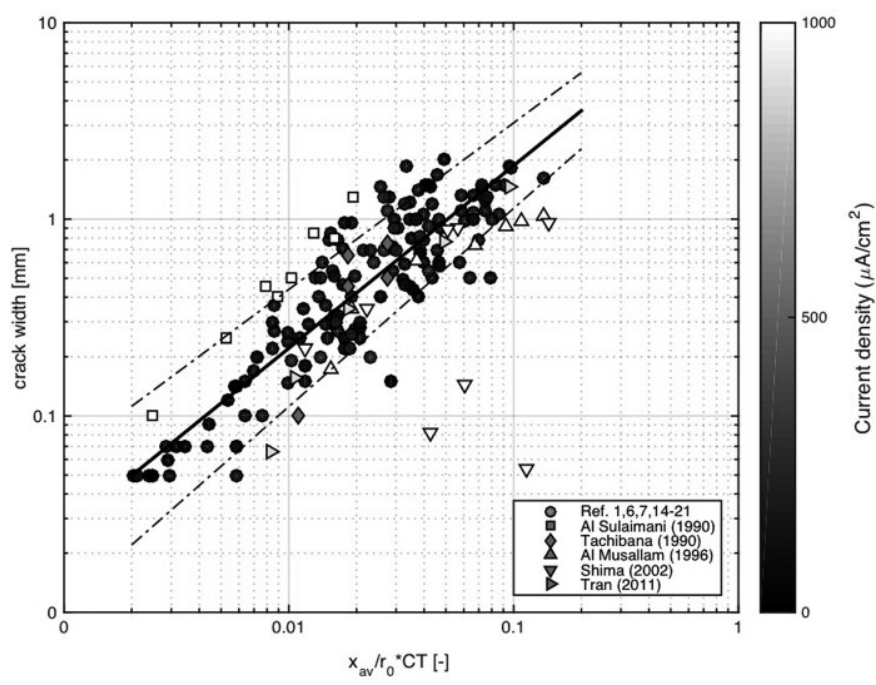

Fig. 8. Maximum crack openings with the average attack penetration related to initial steel bar radius with correction parameter - logarithmic scale; datasets from other experimental campaigns natural conditions and accelerated test setups in terms of the structural consequences of corrosion.

\section{References}

1. L. Giordano, G. Mancini and F. Tondolo, "Reinforced Concrete Members Subjected to Cyclic Tension and Corrosion," Journal of Advanced Concrete Technology, vol. 9, no. 3, pp. 277-285, 2011.

2. Fédération internationale du béton (FIB), Bond of Reinforcement in Concrete: State-of-the-art report, Bulletin 10, Lausanne, Switzerland: Sprint-Druck Stuttgart, 2000.

3. J. Rodríguez, L. M. Ortega, J. Casal and J. M. Díez, "Assessing structural conditions of concrete structures with corroded reinforcement," in Concrete Repair, Rehabilitation and Protection, pp. 65-78, London, UK, 1996.

4. A. Ghersi, A. Recupero and P. P. Rossi, "Influence of corrosion of prestressed reinforcement on the flexure-shear interaction," in Proceedings of the International Conference on Concrete for Transportation Infrastructure 2005; International Congress - Global Construction: Ultimate Concrete Opportunities, Dundee, Scotland; United Kingdom, 2005.

5. C. Andrade, C. M. Alonso and F. J. Molina, "Cover cracking as a function of bar corrosion: Part I-Experimental test," Materials and Structures, vol. 26, no. 8, pp. 453-464, 1993.

6. J. G. Cabrera, "Deterioration of concrete due to reinforcement steel corrosion," Cement and Concrete Composites, pp. 47-59, 1996

C. Alonso, C. Andrade, J. E. Rodríguez and J. M. Diez, "Factors controlling cracking of concrete affected by reinforceter and has been derived for cracks with a minimum value of $0.05 \mathrm{~mm}$, because smaller cracks are hard to detect.
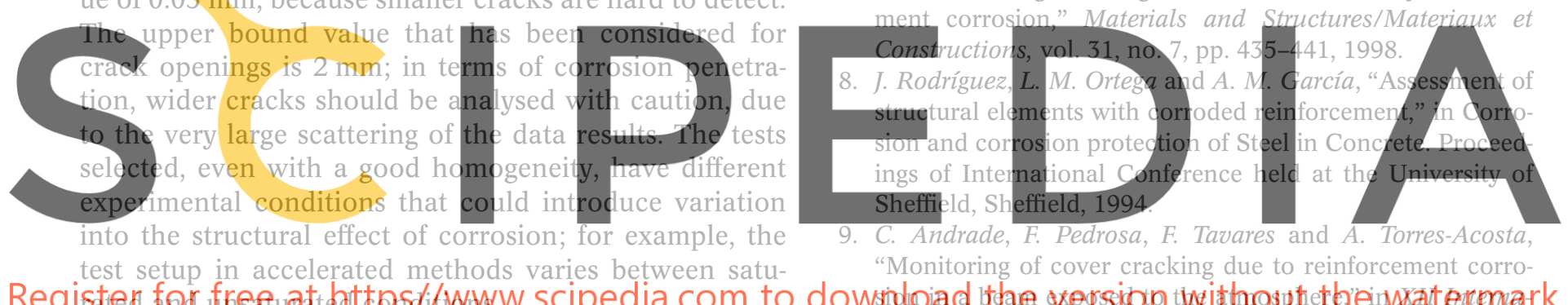

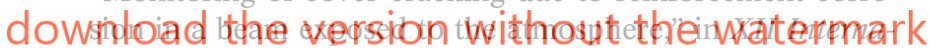
tional Conference on Computational Plasticity. Fundamentals and Applications - COMPLAS XII

10. G. Mancini, F. Tondolo, L. Iuliano and P. Minetola, "Local reinforcing bar damage in r.c. members due to accelerated corrosion and loading," Construction and Building Materials, vol. 69, no. 30, pp. 116-123, 2014.

11. J. Cairns, G. Plizzari, Y. Du, D. W. Law and C. Franzoni, "Mechanical properties of corrosion-damaged reinforcement," ACI Materials Journal, vol. 102, no. 4, pp. 256-264, 2005.

12. A. Torres-Acosta, S. Navarro-Gutierrez and J. Terán-Guillén, "Residual flexure capacity of corroded reinforced concrete beams," Engineering Structures, vol. 29, no. 6, pp. 11451152, June 2007.

13. A. Torres-Acosta and M. M. Martínez-Madrid, "Residual life of corroding reinforced concrete structures in marine environment," Journal of Materials in Civil Engineering, pp. 344-353, 2003.

14. R. Zhang, A. Castel and R. François, "Serviceability Limit State criteria based on steel-concrete bond loss for corroded reinforced concrete in chloride environment," Materials and Structures/Materiaux et Constructions, vol. 42, no. 100, pp. 1407-1421, 2009.

15. J. Rodríguez, L. M. Ortega, C. Andrade and D. Izquierdo, "Calculation of structural degradation due to corrosion of reinforcements," in International conference, Measuring, Monitoring and Modeling Concrete Properties, 2006. 
16. T. A. El Maaddawy and K. A. Soudki, "Effectiveness of impressed current technique to simulate corrosion of steel reinforcement in concrete," Journal of Materials in Civil Engineering, vol. 15, no. 1, pp. 41-47, 2003.

17. C. Andrade and C. Alonso, "Corrosion rate monitoring in the laboratory and on-site," Construction and Building Materials, vol. 10, no. 5 SPEC. ISS., pp. 315-328, July 1996.

18. L. A. Clark and M. Saifullah, "Effect of corrosion rate on the bond strength of corroded reinforcement," in Corrosion and Corrosion protections of steel in concrete, Sheffield, 1994.

19. J. W. Cairns and S. S. Ayop, "Influence of reinforcement corrosion on bond strength," in International Conference, Bond in Concrete, Brescia, 2012.

20. G. Mancini and F. Tondolo, "Effect of bond degradation due to corrosion - a litterature survey," Structural Concrete, vol. 15, no. 3, pp. 408-418, 2014.

21. T. A. El Maaddawy, K. A. Soudki and T. H. Topper, "Longterm performance of corrosion-damaged reinforced concrete beams," ACI Structural Journal, pp. 649-656, 2005.

22. J. Cairns, Y. Du and D. W. Law, "Structural performance of corrosion-damaged concrete beams," Magazine of Concrete Research, vol. 60, no. 5, pp. 359-370, June 2008.

23. A. Al-Harthy, M. Stewart and J. Mullard, "Concrete cover cracking caused by steel reinforcement corrosion," Magazine of Concrete Research, vol. 63, no. 9, pp. 655-667, 1 September 2011.

24. ASTM, Standard practice for preparing, cleaning, evaluating corrosion test specimens, 2011.

25. D. Coronelli, K. Hanjari, K. Lundgren and E. Rossi, "Severely corroded reinforced concrete with cover cracking: Part 1. Crack initiation and propagation," RILEM Book-

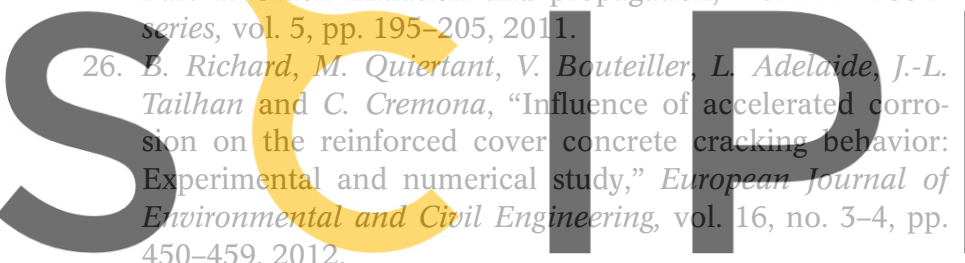

27. M. Prieto, Estudio de la adherencia de armaduras corroìdas

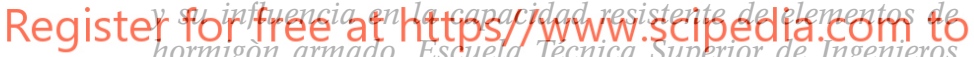
de Caminos, Canales y Puertos, Madrid, 2014

28. G. Al-Sulaimani, M. Kaleemullah, I. Basunbul and Rashee duzzafar, "Influence of corrosion and cracking on bond behavior and strength of reinforced concrete members," ACI Structural Journal, vol. 87, no. 2, pp. 220-231, March 1990.

29. Y. Tachibana, K. Maeda, Y. Kajikawa, M. Kawamura, C. Page, K. Treadway and P. Bamforth, "Mechanical behaviour of RC beams damaged by corrosion of reinforcement.," in Corrosion of reinforcement in concrete, London, Elsevier Applied Science, 1990, pp. 178-187.

30. K. K. Tran, H. Nakamura, K. Kawamura and M. Kunieda, "Analysis of crack propagation due to rebar corrosion using RBSM," Cement and Concrete Composites, vol. 33, no. 9, pp. 936-917, 2011.
31. H. Shima, "Local bond stress-slip relationship of corroded steel bars embedded in concrete," in Proceedings of the third international symposium on Bond in Concrete, Budapest, 2002.

32. A. A. Almusallam, "Effect of reinforcement corrosion on bond strength," Construction and Building Materials, vol. 10, no. 2, pp. 123-129, 1996.

33. Rasheeduzzafar, S. Al-Saadoun and A. Al-Gahtani, "Corrosion cracking in relation to bar diameter, cover and concrete quality," Journal of Materials in Civil Engineering, vol. 4, no. 4, pp. 327-342, November 1992.

34. J. Rodríguez, L. M. Ortega and J. Casal, "Corrosion of reinforcing bars and service life of reinforced concrete structures: Corrosion and bond deterioration," in International conference on concrete Across Borders, Odense, 1994.

35. MC2010, fib Bulletin n66, 2012.

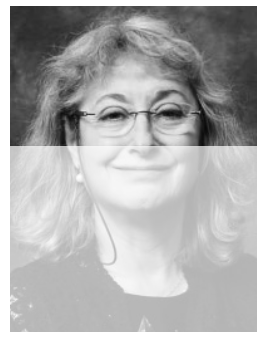

Carmen Andrade

CSIC - Institute of Construction Science of Spain, Eduardo Torroja (IETCC).Serrano Galvache $n^{\circ} 4$. Madrid 28033, Spain andrade@ietcc.csic.es

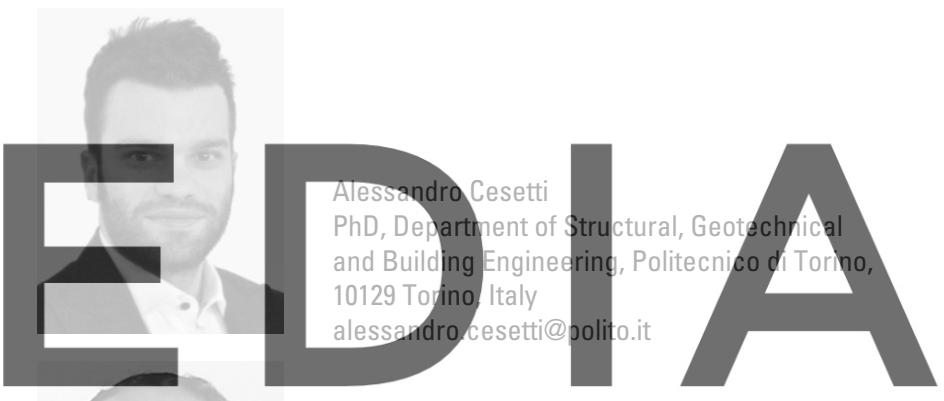

download the version without the watermark

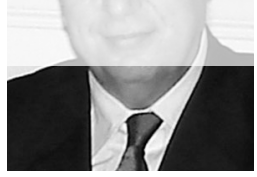

Giuseppe Mancin

Professor, Department of Structural, Geotechnical and Building Engineering, Politecnico di Torino, 10129 Torino, Italy giuseppe.mancini@polito.it

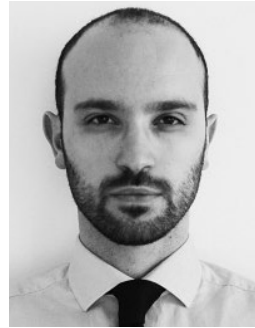

Francesco Tondolo Assistant Professor, Department of Structural, Geotechnical and Building Engineering, Politecnico di Torino, 10129 Torino, Italy francesco.tondolo@polito.it 